\title{
Siobhan Davies and David Hinton in Conversation with Claudia Kappenberg, Part 2
}

Siobhan Davies, Siobhan Davies Dance

David Hinton, Film-maker

Claudia Kappenberg, University of Brighton

\begin{abstract}
In Part 2 of the conversation, Siobhan Davies and David Hinton reflect on the extensive work that informed the first proposal for the film. Key compositional elements are discussed such as the representation of the protagonist through a variety of images from different sources, the decision to represent both the inner and the external world of the protagonist, and, drawing on Étienne-Jules Marey's chronophotography, the decision to work with minutely choreographed image sequences that are composed from archive material. The conversation explores the forensic work with visual details and the intent to draw the viewer's attention to the richness of the found film frames. Davies and Hinton also reflect on the use of damage and decay in Chu-Li Shewring's soundscapes and the roles of film editors Danny McGuire and Matthew Killip.
\end{abstract}

Keywords: All This Can Happen, Portraits, noticing, protagonist, narrative, Muybridge, Marey, Stanley Spencer, Walser, dance, dance film, walking, sculpting, found image, still image, collage, sound

Claudia Kappenberg (CK): We are now looking at the time before you made All This Can Happen $(A T C H) .{ }^{1}$ When I read the proposal for the BFI, I was amazed as to how accurate it was and how closely it envisaged the film. ${ }^{2}$ I was wondering how much and what kind of work you did even before writing the proposal. Could you talk a bit about that?

David Hinton (DH): We worked very hard on the BFI proposal. When Sue and I collaborate, we are quite likely to start from an intuition, but the minute we start to prod at that intuition, all kinds of questions come up. We then try to go one by one and answer all the questions in advance: if we want to do this, we will have to do that, and so on. So you end up having to think your way through the whole process. You start to see all the problems and decisions that are lying ahead, along the road. I suppose I have made so many films now that I can usually see what is going to be difficult. 
CK: Combining an intuitive process with meticulous planning is not easy. Could you say more as to how you went about this?

Siobhan Davies (SD): At the beginning, we took time to talk to each other, to tell each other what was important to us, and what films, dances, writings had influenced useven what frightened us as makers. For example, I spoke to David about Portraits, the second part of Two Quartets from 2007, a dance made for theatre which had not worked as well as the ideas behind it had promised, and David prodded me into saying more about this. ${ }^{3}$

The work involved four dance makers whom I asked to construct a solo which I called a portrait. Each solo was made using the following guidelines: the performers should make material which should mainly face forwards, presenting a front towards the audience. Each artist was then asked to make several strands of material, each one with a specific nature or character to it, ranging from recognizable gesture to movement altered by a change of scale and dynamics. Each strand needed to have clarity of movement and intent, and once that was established each artist could choose how to shift between one strand and another. I was searching for a kind of transparency in the body where one material could fade or intercut with materials from other strands. What was foregrounded at one moment could be superseded or seeped into by another layer. We were aiming to make visible in movement the slips between the concurrent layers of thought and feeling that we continually experience. Using this structure we aimed to shape a "portrait" out of movement and altering dynamics. We all enjoyed the process and learnt through the various difficulties we came across, but by the first performances we had worked out that there was far more to work with. So when David questioned me, it became one of the subjects that interested us both. Portraits unearthed something choreographic that I wanted to do more with, and David could see its potential from his perspective.

Over time, the idea evolved from the three-dimensional performative layering into a testing of several frames within one screen, each one showing a different perspective of a situation or character. One frame was more of a document, one more metaphorical, and another concentrating on a detail or an alternative scale. It helped me that this construction for the film arrived out of a choreographic problem. I felt as if I could begin from something I had already researched and knew something about.

CK: So this is how you arrived at the different threads that are running through the work: the observational, the scientific, the emotional, the historical. What else do you remember from this preparatory process?

$\mathrm{DH}$ : One interesting thing for me about the dance films I have done, is that they often come out of a process which is carefully planned but also very open. I think that's a distinctive aspect of the marriage between the dance and the film worlds. Filmmaking is normally very expensive and therefore requires meticulous planning. You have to 
learn how to visualize things in advance-and, when I say that, it is not just a question of visualizing the shots you want. Rather, it is a question of thinking: if it starts raining, what do I do then? How am I going to cope with the actual circumstances that I will be in? So the filmmaking process is often something like a military campaign, where you imagine all contingencies, then make your plans, and finally execute them. I think the dance world, on the whole, is inclined to have a much more open process throughout. You can correct me about this Siobhan. The practicalities of dance are so very different from the practicalities of making films.

SD: There are huge variations on how a dance can be made. I usually begin with the knowledge that I am going to be working with a living person with their own unique relationship to their own body as well as to everything else. All of the hardware and decisions that David is talking about will probably not be part of my initial work. Instead, our own histories give us plenty to think about, and the body is a structure already with its own necessities. We have a constant presence, gravity, and our own anatomy. Hence, when I begin to make work with a performer we can bring out the nuances of human behaviour and human timing, and these materials, our very liveness and how we shape what we are or can be in the continuous present, is very different from film as material.

DH: Even after we had written the BFI document, the work had hardly begun. That document laid out a set of principles, but so much of the actual work lay in deciding what kind of archive images we were going to use to make the film. It was almost limitlessly open, because, in a way, Walser's Walk contains the whole world. ${ }^{4}$ There was a terrifying amount of openness as to what images we might use. Then, even when we decided what kind of images we wanted, we still had to find them. That's the thing about working with found images, the images do have to be found! And that can be a massive enterprise, like an archaeological dig, where you have to shovel through tons of rubble before you find a single piece of treasure. We might easily watch three hours of documentary footage to find three seconds that we wanted to use, or we might look at two hundred stills to find two that we wanted to use.

CK: The BFI proposal also identifies the overall aim of the project and states: "The aim of the film, like the story, is to share one individual's perceptions of the world, to take us inside the consciousness of the walker, and to show how he sees, feels and experiences things." ${ }^{\prime 5}$ This is a familiar format in modernist literature, where you have the figure of the urban passer-by who observes the modern city, but it is a more unusual starting point for a choreographic project which would normally show the protagonist himself and what he or she does. In ATCH, you turn this around and we mainly see the narrator's context, the world in which he lives. We see the world through his eyes and through his experiences. Could you say how you came to this kind of approach? 
DH: Most films represent people by showing what those people do. Did you see that film Wild (2014) with Reese Witherspoon? ${ }^{6}$ That's a film about a woman going for a walk, but the protagonist is represented as an active agent in every scene. What we wanted to do in ATCH was to try to render subjective experience, not showing our protagonist as an active agent, but representing through images what's going on in his head. We were experimenting with a different way of portraying character in a film, and we made many interesting discoveries - including the fact that you don't have to have the same person representing your protagonist throughout the film. In ATCH, we have all kinds of different people representing the protagonist. We'd find somebody in the archives, who would seem to us to be the right character to represent the narrator in a particular scene, and over the stretch of the film, there must be ten or fifteen different people. What fascinates me is that no viewer has had any problem with that. For me, that is a revelation and also great news, since I always want to experiment but I never want to confuse the audience.

SD: I am always intrigued by the extra-ordinary movements which are also the common ones to all of us, and our stories are often embedded in them. For example, the walk employs every part of us: from the desire to do it; dealing with gravity; the state we are in; what we want to reach; what else we might be thinking and experiencing; to the immense orchestration of every part of our anatomy adjusting, responding, and balancing all in the right timing with the right variations of intensity. Before finding the Walser novella, David and I were wondering how we could illuminate the different perspectives of one situation. And we were curious about how we could show both an experience and what was going on externally. We hoped that using several frames on one screen would give us the opportunity to create multiple and concurrent renditions of thought and experience.

CK: What sort of visual material did you research to inform the visual style and approach?

SD: Both David and I knew of Muybridge, and I have a love of Fox Talbot. I was thinking of the qualities, colors, and textures of early photography, and David was researching the earliest photographs of movement. He discovered a website on Étienne-Jules Marey, and we were delighted by his sequential photographs of movement, one action being the walk. They were not films but a series of still frames, ten to fifteen maybe, each one giving us an observation of distinct moments that are the elements of a fluid action. Marey was a scientist, and his studies include chronophotography in which lights on the body, filmed in the dark, are used to visually describe the pathways of certain joints in relationship to each other. These images are graphically beautiful, both ghostly and clearly revealing the position of the joints.

We also looked at cubist painting, where one object can be seen from different perspectives at the same time. We looked at the works by Stanley Spencer which show 
men at work, people who are sometimes in half way positions of activity with a sense of rhythm going across from one body to another. I can remember The Furnaces shoveling coal into a furnace, or Bending the Keel Plate. ${ }^{7}$ Furthermore, I found early natural history films at the BFI in which we both felt the freshness of the filmmakers. What they were filming may never have been filmed before! Eventually we searched for the earliest photographs or films of a subject or of actions in Walser's The Walk which we could find. But the prints themselves showed their age, they had become scarred, bleached, partially erased over time and had, to me, a correlation with the weathering decomposition of the protagonist and us.

CK: In the BFI proposal you also address this play with multiple images: "It is a dance of mental images, where everything is connected by association within a single psyche." ${ }^{8}$ How did you come to see this as a dance? What makes it a dance?

$\mathrm{DH}$ : I think one way you can regard dance is simply as a way of looking at the world. It has certainly been that way for me. Through spending a lot of time with dancers, and working with them, I have come to look at the world differently. I'm sensitive to different things in an environment. That, in itself, has had a big influence on me as a filmmaker. And then, when it comes to making dance films, I'm always thinking about the fundamental affinities between dance and film. Not only are they the two art forms based on the principle of movement, but also making a dance and making a film are fundamentally similar activities in that they are both about giving structure to action. Or you might call it "giving structure to movement." A big breakthrough for me was thinking about the fact that, in a film, movement doesn't necessarily have to be supplied by the body of a dancer. You can use the camera as a tool to go out into the world to harvest movement, and you can use the editing room as a means by which to structure that movement. Once you start to think that way, the possibilities of what a screendance might be are massively expanded. You open the door onto the possibility of "making the world dance." From there, it is quite a small step to making a dance out of somebody's mental world-which is what we are doing in ATCH.

Also, if you think about the mental world of a person on a solitary walk, it is likely that several different kinds of images are going to co-exist in their mind at the same time. The solitary walker is aware of the world around him, but he is also deep in thought, turning over all kinds of things in his brain: memories and dreams, fears and desires, frustrations and illuminations. And, of course, what makes our film into a dance that is choreographed, rather than simply a confusion of images, is that we are carefully choosing the images we use, carefully placing them on the screen, and carefully juxtaposing them with each other. We then work hard on how one image moves in relation to another, and the timing of that movement, so that the whole of our dance has a constructed rhythm and music to it. 
CK: Erin Brannigan and Cleo Mees focus on the question of the dance in their essay on ATCH and explore "how the film evidences the choreographic work undertaken in process." 9 They ask, "How do the disciplinary skills of dance figure amongst the strategies, techniques, and paradigms of the cinema?"10 Not wanting to create definitions of dance and choreography, they ask: "how can we think about how key choreographic terms and strategies such as weight, breath, tone and flow [...] are apparent in the film's composition?"11 Might you have thought in those terms when selecting and editing the material?

DH: The terms that Erin and Cleo use-weight, breath, tone, and flow-can, I think, be usefully applied to any composition that unfolds over time. I could imagine a musician using those terms, and I can certainly imagine a filmmaker using them. For me, it goes back to the whole question of creating a structure in time. Tarkovsky famously described filmmaking as "sculpting in time" and that is what dance-making is too. ${ }^{12}$ Once you are shaping something in time, you inevitably have to think about where the breaths are going to be, when you want things to flow and when you don't, and so on. In film-making, those things are determined in the editing, so you will always hear terms like breath and flow being used in the cutting room. A term like weight won't have quite the same value as it would when a choreographer is working with a live dancer, but I could still imagine using it when working with an editor.

SD: Weight, breath, tone, and flow are not words I use when choreographing or working with others. I have to deal with weight, tone and flow, but I don't call them by those names. With regards to weight, I might use terms relating to varying densities of muscular use or the idea of lightness of touch. How weights and strengths of imagination can influence the nature and character of a movement. Tone is not a word I use either, but I enjoy seeing a variation of attention to a movement, or the lightness and darkness in an image which feels like the equivalence of tone. Sequential movement also means more to me than flow, because the latter seems to erase the exactitude of moment-to-moment revelations. If a dancer breathes in, they must breathe out. If an arm rises, it needs to come down. In my earlier work I was always engaged with this logic and constancy of presence, but this fluidity began to represent something inhuman to me. Where were the difficult or tangled lines of thought, feeling and responses which are part of my day-to-day life? I wanted movement to look more like my thinking, given it is my thinking!

A step which helped me towards breaking up fluidity, and which is relevant to ATCH, was when I worked with the Composer Matteo Fargion who introduced me to replacing each note in a score with a precise movement, forcing me to work with movements that are not necessarily anatomically connected. During David's and my preparation time, we translated this concept and re-sequenced a series of frames of movements according to a score. At first these felt as if I was de-oxygenating the 
movement. But I was also thrilled by this new relationship to movement in these tiny increments.

Exploring sequencing earlier on in the process, David and I also reconstructed the movement of a young soldier bearing arms in different ways. This is a study by Marey. But soon David pointed out that we did not want to be gods manipulating figures. I completely understood this lesson, especially when we worked with an older figure, also by Marey, who, in the film, demonstrates how his stomach worked while breathing. We did far less with him, paused his action, made brief repeated phrases. This slight re-choreographing of the frames of action did just enough to make his movement less of an exercise and more about a particular moment in time. This was the kind of dimension we were looking for.

CK: David, you have made this kind of work previously, where you develop a choreography solely through the repurposing of material.

DH: The first dance film I made using archive images was Birds (2000), over fifteen years ago. ${ }^{13}$ It came about because the more I worked on dance films, the more aware I grew of how much of the choreography was actually taking place in the cutting room. I was working with dancers who were creating movement, but much of the ordering of the movement-giving it shape and structure and rhythm—was happening in the editing. I began to realize that film editing is itself a choreographic activity, and that led me to think: why not make a dance film where all the choreography happens in the editing? Around the same time, I was standing at a bus stop in Leeds, watching birds flocking over the town hall, and it occurred to me that birds had a wonderful vocabulary of movement. I thought it was completely legitimate to use that as the raw material for a dance, so I ended up making a film, together with Yolande Snaith, where we found all the movement content in archive footage of birds, and then we choreographed it entirely through the edit. Some people at the time were outraged, and refused to accept this as a dance film, but now, I think, it is better understood.

SD: This was however not the starting point for $A T C H$. The idea of using archive images came later in the process.

DH: Yes, we started from the idea that the whole field of dance film is vexed and difficult, and that one way we could get a fresh perspective on it was to go back to the very beginning - to look at the very first experiments in trying to render movement in a sequence of images. This led us to the work of Marey. But our interest in Marey also came from thinking about how mundane things can become magical. When Siobhan first suggested that we should make a film about going for a walk, my immediate fear was that it would be very boring. I asked myself: when has walking ever been interesting in a film? My mind went almost immediately to Muybridge and Marey. When they made their first experiments, it was a miraculous thing to see a moving image of a man walking - even if it was only two steps. I still feel that miracle when I 
look at their work today, and this was a crucial inspiration. To be honest, it still makes me feel a little giddy to look at Marey's work. I feel that I'm confronted by the most profound magic and poetry of cinema, that I am looking at a moment of time saved from oblivion. A still image can freeze a moment in time, but a moving image is like a resurrection-it brings a moment in time back to life. Think of Marey, in the middle of the nineteenth century, setting up his camera and filming a soldier jogging across a field. Then look at those two seconds now, as a moving image, and it all comes back to life: the soldier's pack is still weighing heavy on his back, the grass is still moving gently in the wind, even though that soldier is now long dead. It is profoundly moving - that resurrection of lost time.

CK: Besides bringing Marey's scientific enquiry to life, you also place his work amongst very different kinds of visual material. What was the intention behind that?

$\mathrm{DH}$ : Every found image enriches the film by bringing its own history and its own story with it. It is very obvious in $A T C H$ that every image is being re-purposed-that it was originally shot for an entirely different purpose-and I love this for many reasons. Most importantly, it makes each image deeper and richer than a specially shot image would be, because each found image brings its own dancing aureole of associations with it. If we use an image of a striking worker from a newsreel of the 1930s, that single image conjures up all kinds of historical associations, but also, because it has been torn from its original context, it brings a mystery: what was the reason for which this image was actually shot? What was the story it originally belonged to? I don't expect any viewer to be thinking consciously about this, but each image enriches our film with the mystery of its origins. It drags into our story the residue of many other stories, resonating away down the echo chamber of time. That's a beautiful thing.

The use of found images also means that nothing quite fits with anything else; the images don't match each other. Yet they are finally part of the same structure. I like this feeling that each image is distinct and separate-worthy of consideration in its own right-and, at the same time, one brick in a larger edifice. Your mind is encouraged to take in both the separateness of each fragment and the unity of the whole. This is a characteristic of collage, I suppose, and has always appealed to my sensibility.

Another reason for using found images from the archives was simply that Walser's story was written in 1917, and we wanted to create a world that he would recognize as something like the world he was describing. And finally, there's a practical reason for using old images, and that is that they are often out of copyright. So if you go to the right sources, you can get images cheaply or even for free. I doubt that we could have afforded to make the film if we had used modern images. 
CK: Archival images are more, shall we say, "noisy" than specifically shot images, and because of all these other places, times, events and relations they refer to, they also come across as more "real".

DH: Yes, a lot of the images were originally documentary images, and we have pressed them into service in what is essentially a fiction. This is interesting, because documentary images appear "truthful" in a way that makes our fiction feel "truthful" too. Often in documentary the action is not being performed for the camera but observed by the camera, and there is a precious authenticity about that. At the same time, all the images in the film are presented in such a stylized way that I don't think the viewer will ever feel confused or misled about what is going on. It is now part of the richness of the film that it contains not only many different qualities of image, but also many different qualities of performance. In fact, just about every different kind of relationship than a person can have with a camera exists in our film, from extreme selfconsciousness to a complete lack of self-consciousness. We might cut from someone performing directly to the camera, to someone far off in his or her own world, unaware that there is a camera present. In theory, these different performance modes probably shouldn't work together, but they do.

SD: After much experimentation, we decided to collect frames from different sources. We looked at fiction films, as well as documentary and home movies, but it was the last two categories that seemed the richest to us. Early photography was a science and helped to support an urge for being able to take the time to look. The documentaries were amongst the first films to capture people's behavior both at work and enjoying themselves. The natural history films explored the world through different lenses and scales. The home movies showed both the very affected and unaffected attitudes towards a lens. Everything I saw woke me up to a past.

DH: Another thing I like about using found footage is simply the economy of using recycled images, rather than shooting more stuff to add to the proliferation of images in the world. There is something almost nauseating about the number of images in the world now, and something unnecessary about it too. If you need an image of an apple in your film, do your really need to go out and shoot another image of an apple to add to the millions that already exist? So, one of our ideas was to go back as early as we could and use the first version we could find of each image that we wanted. That meant that our image of an apple was shot a hundred years ago-in about 1910—and it is a very special and beautiful image, because it was filmed using a very early color process. That gave it a unique color quality which you could never replicate in a modern image.

CK: Siobhan, you have talked about a forensic aspect in the work, could you expand on that? 
SD: The forensic approach was used initially to draw attention to the more microscopic details which, if focused on, would add to the story. Maybe the forensic could highlight the emotional, as in the case of the botanical filming of the opening of a flower which in the context of the film is sexual. We could also choreograph tiny changes in an expression on the tailor's face, or play with the man remembering his cruelty to enhance the narrative, but in minute moves. The forensic allowed us to open up to different scales amongst the different frames.

CK: As part of this detailed work you have repeatedly frozen the action and created series of still images that suggest and promise movement. But quite often, all the viewer gets is a splitt second of a movement and then there is another still. To me, this felt like a cat on a string kind of experience. The play between movement and stillness was teasing me and playing with my expectations. Did you want to hold back on movement?

SD: When I made work for the theatre, I loved stillness on the stage and also the anticipation of something about to happen. Or I would allow for a sudden burst of movement and then reduce it to very little, but allow for the echo of a surge of movement. Sometimes I tried to think of movement phrases as a sentence structure; which movement is a noun, and which one is a verb? Where is the full stop or comma? While making the film, I could borrow some of that thinking when choosing which movements were still. For example, the children playing with the hay is very active. It's a game when they throw hay at each other, and it is a kind of chaos. How could we capture this? The hay in the air was a movement that would bring a particular kind of joy as to how the hay would separate and be suspended. But when you move from the child throwing to the hay being up in the air, you would need to find exactly the right timing in which you would feel the action even if you had edited some of it out. And when your eyes were given the chance they could witness a sliver of the unexpected or experience two things at once that are normally separated in a sequence.

DH: If you take the shot of the children in the hay, it starts off as straightforward documentary footage. Out in the world, some children are playing and the camera is recording it. It is not choreographed. But when you take that sequence into the cutting room you can start to choreograph it by freezing it here, speeding it up there, and then freezing it again. Then you are choreographing, because you are imposing your own time structure onto the raw action. A lot of our ideas about working in that way came from our experience with the Marey films. In his era, two seconds was a very long film. It might be 40 frames long and that makes every frame very important. The other thing is that, in a filmstrip that is 25 frames long and 150 years old, all the frames have aged in different ways. Hence every frame has its own character, and we became very interested in that. The damage and decay in frame 18 might give that frame its own special beauty. 
SD: So we made sure we would freeze on frame 18 , and it may be partly abstracted by having a big patch of white light over the body.

CK: As an audience, I shift my attention when I see such a still, away from the narrative. For example, in the sequence in the foundry with the shovel, those stills are gorgeous and make me look at the shapes and the play of light and dark.

$\mathrm{DH}$ : Well, that sequence with the shovel is supposed to give you pleasure. Normally, in a documentary, you will have a guy shoveling coal into a stove and it will be great, but you won't have time or space to relish it as something great in itself. The mantra in the conventional film world is "murder your darlings," meaning that all incidental pleasures must be sacrificed to the forward drive of the story. We are deliberately resisting that. One of the things we're trying to do in $A T C H$ is to encourage the viewer to consciously enjoy things that would slip past in a more conventional film. We are using various tactics to say to the viewer: "Hey, look more carefully at this, isn't this great?" In the case of the shoveler, we imposed a kind of chronograph effect onto the images to make you vividly aware of the shape that his body is making and the dynamic of his action. It is only through working in the dance world that I could have arrived at this way of working with images. And, of course, by using this device, we are also saying: look, this is dance.

SD: The same applies to the scene where a man steps from one girder to another but remains constantly poised in between. You see the beauty and danger of this one step. By stilling the image, another narrative is quietly inserted, perhaps giving rise to a more precise kind of noticing of the in-between moment-one the eye or the mind does not normally hold — but letting that instant fill us.

$\mathrm{DH}$ : That is a key thing. Siobhan is really into noticing things, and that is one of the reasons why she wanted to do a film about a walk in the first place. A lot of what we have made is simply about what you notice when you go on a walk-and that feeds into the guy with the shovel. We are saying: look at this. We are being emphatic. Although the image is humble, we are emphatically saying: look at what's happening in this image. It's a quiet way of shouting.

SD: As we were speaking about Marey, the damage in the images, and the lightDavid said to me early on that film is made out of light. This is very obvious to him, but there is something thrilling to me about that. I have occasionally wanted to imagine my body as being more transparent, and working with the idea of people and places made out of light was intriguing. One way of working is not replaceable by the other, but working in film provided me with another way of saying, "look at what is happening in layers of light and time," in ways I can not achieve with a live performance. 
DH: Many of these things that we are talking about here are to do with the fact that I want the viewer to have dual responses to what they see. I don't want the viewer to be seduced to the degree that they forget that they are watching a film. That's the kind of ambition that a Hollywood director might have. I want the viewer of ATCH to be both absorbed by, and alienated from, the content of the film. When they see an image of a man walking down a country road, I want them to be able to identify with that man, to feel drawn into his story, while at the same time having a powerful awareness that he is just a pattern of light on a screen. For me, that duality of response is very exciting and moving, that feeling that there is somebody there and nobody there at the same time.

CK: Besides working with light instead of real bodies, you also had to work with a flat and defined screen space, instead of the three-dimensional space you have in live work. How did this compare?

$\mathrm{DH}$ : Early on in the process, if Siobhan saw a walking figure on the left-hand side of the screen, she would expect that figure to cross the screen and disappear out of the righthand side of the screen. Her first instinct was to think of the screen as though it were a space like a proscenium stage. It was hard for her to get used to the idea that, on screen, a figure can keep on walking forever without travelling anywhere at all. In fact, the figure can be looped so that he/she walks for an hour and remains in exactly the same place. This was a classic example of the difference between theatrical and cinematic thinking.

CK: Thinking more about the bodies on screen, ATCH also explores what happens to bodies in the 19th and 20th centuries, through references to industrialization and war, and through the different image technologies you deploy. Siobhan was talking earlier on about how these bodies have become scarred, bleached, and erased with time, and that this says something more broadly about aging and decomposition. Is ATCH also an act of remembrance?

$\mathrm{DH}$ : I think its important to remember that, although we use a lot of very old images, the work that we have made is a modern creation, entirely dependent on modern technology. Our whole work process was based on being able to put many different moving images on the screen at the same time. And we needed the freedom to juxtapose images, to play with their sizes and shapes, to slow one down and speed another up, and so on. The technology that allows you to do all this, while working on a low budget, has only arrived recently. So what we've made may even count as a pioneering or cutting-edge endeavor in terms of collaging and compositing moving images with cheap modern technologies.

The finished work echoes the modern experience of sitting in front of a computer screen, with many different windows open, watching several images on the screen at the same time. Much of the technique and sensibility of the work is, I think, entirely 
contemporary. There's a perception, perhaps, that it is "nostalgic" to make use of ancient images, but that's not how I see it. For me, ancient pictures are often simply more fascinating to look at than contemporary ones. Most of what is in a modern photograph is dull because of its familiarity, whereas a photograph of the same scene taken in 1918 is fascinating, because it is less familiar. Something as mundane as a man's hat or his moustache becomes interesting, because we don't see hats or moustaches like that any more. I subscribe to the idea that "the past is a foreign country," and I think it is great if a film takes you to a foreign country, rather than showing you what you can see outside your front door. ${ }^{14}$

CK: There is also the sound world of ATCH, yet another layer of textures and impulses, if not several layers with the narration and the sounds that complement the narration. Could you talk a bit about the conversations you had with the sound designer Chu-Li Shewring?

DH: As with almost any film, the soundtrack is more than half of the film. What made ATCH really interesting from the sound point of view is that there was no sync sound to work with. Every image that we used was either shot before the era of synchronised sound recording, or else it came from the kind of film that doesn't have sync sound, like a home movie. Well, there's one exception-the scene where the young boys do bird sounds-but, apart from that, I don't think there's any sync sound in the whole film.

Of course, that is unusual in a modern film. It meant that our sound designer, Chu-Li Shewring, had to create the whole sound track from scratch. It meant she had to do a massive amount of work, but creatively it was hugely beneficial, I think, because ChuLi had to put real thought, energy and invention into every single second of the film. And the result, I think, is magnificent. Chu-Li made a soundtrack that is utterly contemporary in its subtlety and sophistication, but the sounds that she chose to use are entirely appropriate to the ancient images. Chu- $\mathrm{Li}$ is an absolute genius. She picked up on the way that we were playing with damage and decay in the images and she made that a feature of her sound textures too. She used this in really witty ways. And, if we were looking for a single distinctive sound to punctuate the action, she always found exactly the right one. There's a sound of a cork coming out of a bottle in the "Alice In Wonderland" section that still makes me laugh every time I hear it. Also Chu-Li made many inspired music choices. There's a lot of very strange and diverse music in the film that viewers are probably not even aware of, because its not music laid on with a trowel, but music simmering away in the mix in such a way as to create exactly the right atmosphere. You might half-hear a distant voice on the soundtrack that is wonderfully evocative, and, if you look into it, you'll find that its a few bars of a Romanian folk song that Chu-Li has found. 
What it all adds up to is a soundtrack that, for me, succeeds brilliantly on both a representational and expressionistic level. The sound animates the images and brings them to life when it needs to, but it also does much more than that, because it offers an audio representation of the mental world of our protagonist. Another crucial thing that we had to get right in the sound was the voice of the narrator, and I don't think we could have had a better performance than the one we got from John Heffernan. For me, he got the tone and the manner absolutely right. Every time I see the film, I still get pleasure from the way he does the narration. The same goes for Chu-Li's sound design, I think it's magnificent.

CK: What about the film editors Danny McGuire and Matthew Killip. How did you work with them, and what was their contribution to the film?

DH: Well, Danny was certainly one of the heroes of the production. If ever there was a film "made in the editing," then it is this film, and Danny was central to the process from beginning to end. He was our technical wizard and he was also a core member of the creative team, because one of our key ideas from the beginning was that we were going to use editing as a "way of thinking" and a "way of creating" on this production.

We always thought of the compositing work-the arrangement of shots on the screen-as choreographic, and getting it right involved endless experimentation. You have to remember that Siobhan had never thought of herself as a filmmaker, and yet it was crucial to our conception that she be involved in "choreographing" the images on the screen. What this meant in practice was that she often worked with Danny with the same intensity that she might work with a dancer in the studio. The two of them would sit together for hours in front of the computer screen, experimenting with different ways of orchestrating the images within the frame. So this central aspect of the process was entirely based on Siobhan using Danny's film knowledge in tandem with her own dance knowledge.

SD: It was an extraordinary partnership to work alongside Danny. My creative environment became microscopic. Instead of having the palpable use of space and time of a stage or studio to work with, I could hold the image of something huge virtually in my hand. I had the kind of time we never have in a rehearsal studio. I could see a frame side by side with another again and again and make minute adjustments using my choreographic learning. I felt sucked into exquisite minutiae. Danny had great patience, kindness, and was very perceptive with regards to my searchings and our working side by side was a joy, although my heart was in my mouth a lot of the time. I need to also add that I have never worked with sound in the way that Chu-Li introduced me to. Again, microscopic in the details. She used unorthodox sounds to make a specific moment more poignant alongside John's reading of the text. I felt as if my sense of hearing was intensely employed, and the detailed soundscape now also enhances the audience's experience of the film. 
$\mathrm{DH}$ : Then there was one period in the edit when Danny had to go off and do something else, so Matthew Killip took over his role for a while. That turned out to be serendipitous because Matthew is a director as well as an editor, and he brought his own unique sensibility to the work. There is definitely something about Matthew's way of seeing, thinking, and feeling that enriches the parts of the film that he worked on. Those sections have a special kind of beauty that belongs to him. So we were really lucky in all the collaborators we had.

CK: And how did you suture the whole thing together?

DH: Well, very early on in the process, we went through Walser's story and broke it down into about twenty-five different episodes, which gave us a kind of script, and a way of organizing all our thinking and all our raw material. But then, for a long time, we worked on sound and images quite separately. We talked to Chu-Li about each episode, and she went off and started assembling a sound world for each one. Meanwhile, quite independently, we worked with Danny on choreographing the images for each episode. Then Chu-Li would turn up with some sound ideas, and these would affect what we did with the images. Then we would perhaps send Chu-Li a rough-cut of the images and she would re-jig her sound to the rough cut. So the more the film was refined, the more the visual world and the sound world were drawn together. At the very end, the sound was tailored to make it absolutely frame-accurate to the finished picture.

Some of the cruelest decisions at the end were to do with cutting things down and leaving things out. Our work process meant that we would often work for a long time on the compositing of a single sequence of images, only to discover that that sequence then went on too long in relation to the film as a whole. So many things that we liked had to be cut out, in order to make the film work finally as a single structure.

CK: I very much like your notion of being "sucked into exquisite minutiae," Siobhan. This describes so much of what is going on in the film and what the work offers to its audiences. Siobhan and David, thank you very much for this conversation.

\section{Biographies}

Siobhan Davies is a renowned British choreographer who rose to prominence in the 1970s. Davies was a founding member of London Contemporary Dance Theatre and in 1982 joined forces with Richard Alston and lan Spink to create the independent dance company Second Stride. Founding Siobhan Davies Dance in 1988, she works closely with collaborating artists to ensure that their own artistic enquiry is part of the creative 
process. By 2002 she moved away from the traditional theatre circuit and started making work for gallery spaces. Davies applies choreography across a wide range of creative disciplines including visual arts and film. In 2012, Davies created her first film work All This Can Happen with director David Hinton.

\section{Email: info@siobhandavies.com}

Film-maker David Hinton has won a host of awards for both his documentaries and his screendance works. He has made many films about the arts for television, including portraits of Francis Bacon, Michael Powell, Alan Bennett, and Little Richard. He has also made films about Dostoyevsky, visual comedy, and the Cultural Revolution in China. He has made film versions of two stage shows by DV8 Physical Theatre-Dead Dreams and Strange Fish-and he has collaborated with many choreographers to create original dance works for the screen. He has led dance film workshops all over the world.

\section{Email: davidhinton1@gmail.com}

Dr. Claudia Kappenberg is a performance and media artist and Course Leader for the MA Performance and Visual Practices at the University of Brighton, UK, as well as founding editor of The International Journal of Screendance. She has published widely on performance and screen-based work, including in Anarchic Dance (Routledge, 2006), The International Journal of Performance Arts and Digital Media (2010), Art in Motion (Cambridge Scholars, 2015) and the Oxford Handbook of Screendance Studies (Oxford University Press, 2016). Her performance practice consists of minimal choreographies which have been shown across Europe, the US, and the Middle East in the form of live interventions, gallery-based performances, and screen-based installations.

Email: C.Kappenberg@brighton.ac.uk

\section{Notes}

${ }^{1}$ All This Can Happen, Davies and Hinton.

2 Davies and Hinton, "Film Proposal for the British Film Institute," 2012. Published in this issue 175-181.

${ }^{3}$ Davies, Portraits (2007).

${ }^{4}$ Walser, The Walk and Other Stories. The text was edited for ATCH by Siobhan Davies and David Hinton.

${ }^{5}$ Davies and Hinton, "Film Proposal," 177.

${ }^{6}$ Vallée, Wild. 
${ }^{7}$ Spencer, The Furnaces; Spencer, Bending the Keel Plate.

${ }^{8}$ Davies and Hinton, "Film Proposal," 178.

${ }^{9}$ Brannigan and Mees, "Breaths, Falls, and Eddies," 40.

10 lbid.

11 lbid.

12 Tarkovsky, Sculpting in Time.

${ }^{13}$ Hinton and Snaith. Birds.

${ }^{14}$ Hartley, The Go-Between. Prologue.

\section{References}

All This Can Happen. Dir. Siobhan Davies, David Hinton. Prod. Siobhan Davies Dance, UK: 2012. See http://www.siobhandavies.com/works/all-this-can-happen/.

Birds. Dir. David Hinton and Chor. Yolande Snaith. BBC, Arts Council England, RPS, UK: 2000. Film.

Brannigan, Erin and Cleo Mees. "Breaths, Falls, and Eddies in All This Can Happen: A Dialogue." The International Journal of Screendance 7 (Fall 2016): 39-53.

Davies, Siobhan and David Hinton, "Film Proposal for the British Film Institute." The International Journal of Screendance. 7 (Fall 2016): 175-181.

Hartley, L.P., The Go-Between. London: Penguin Books Ltd, 2004.

Portraits. Part of Two Quartets. Chor. Siobhan Davies. Perf. Siobhan Davies Dance, UK: 2007.

Spencer, Stanley. Bending the Keel Plate (1943), Accessed 7 Oct 2016.

http://www.iwm.org.uk/collections/item/object/25164

Spencer, Stanley. The Furnaces (1946), Accessed 7 Oct 2016.

http://www.iwm.org.uk/collections/item/object/25167

Tarkovsky, Andrei. Sculpting in Time: Reflections on Cinema. Trans. K. Hunter-Blair. Austin: University of Texas Press, 1986.

Walser, Robert. The Walk and Other Stories. Trans. C. Middleton et al. London: Serpent's Tail, 2013.

Wild. Dir. Jean-Marc Vallée. Fox Searchlight Pictures, US: 2014. Film. 